\title{
Perché io son nata poeta, non santa: a voz da mulher e a poesia de Gaspara Stampa
}

\author{
Beatriz Rodrigues de Souza \\ Universidade de São Paulo \\ beatriz.rodrigues.souza@usp.br
}

RESUMO: Ao longo dos anos, o amor foi representado de diferentes formas e em meios de comunicação diversos. O poeta italiano Petrarca, por exemplo, expressa seu sentimento por Laura usando a forma tida como perfeita: o soneto; além disso, seu amor é sempre puro e sua musa sempre calada. É assim, sem voz e apenas para admiração, que as mulheres aparecem na maioria das obras de arte, refletindo os ideais sociais do período em que estão. Porém, surgem autoras que subvertem essa ideia; é o caso, por exemplo, de Gaspara Stampa, poeta do Cinquecento italiano. Embora a autora siga a forma poética consagrada por Petrarca, usa sua poesia para manifestar seu sentimento e, assim, consegue ser uma voz feminina em um meio em que existem poucas oportunidades de expressão para as mulheres. Neste artigo, a figura da poeta é colocada em oposição ao modelo imposto a partir de uma citação de outra autora italiana, Sibilla Aleramo; embora as autoras sejam separadas por séculos, percebe-se que a visão de amor e do feminino que prevalece em ambos os períodos é aquela masculina. Faz-se, então, necessário o estudo dos escritos dessas e outras mulheres para que haja um espaço para suas (e nossas) vozes.

Palavras-chave: Literatura feminina. Gaspara Stampa. Papel de gênero.

ABSTRACT: Nel corso degli anni, l'amore è stato rappresentato in modi diversi e in vari media. Il poeta italiano Petrarca, ad esempio, esprime il suo sentimento per Laura usando la forma considerata perfetta: il sonetto; inoltre, il suo amore è sempre puro e la sua musa è sempre silenziosa. È così, senza voce e solo per ammirazione, che le donne compaiono nella maggior parte delle opere d'arte, riflettendo gli ideali sociali del periodo in cui ci sono. Tuttavia, appaiono autrici che sovvertono questa idea; è il caso, ad esempio, di Gaspara Stampa, una poeta del Cinquecento italiano. Sebbene l'autrice segua la forma poetica consacrata da Petrarca, usa la sua poesia per esprimere i suoi sentimenti e, così, riesce ad essere una voce femminile in un ambiente in cui ci sono poche opportunità di espressione per le donne. In questo articolo, l'immagine della poeta è contrapposta al modello socialmente imposto a partire da una citazione di un'altra autrice italiana, Sibilla Aleramo; anche se ci siano secoli tra le autrice, si vede che la visione dell'amore e del femminile che prevale in entrambi periodi è quella maschile. Quindi è necessario studiare quello che hanno scritto queste e altre donne perché ci sia una spazio per le sue (e nostre) voci. 
Parole chiave: Letteratura femminile. Gaspara Stampa. Ruolo di genere.

ABSTRACT: Over the years, love has been represented in different ways and in different media. The Italian poet Petrarca, for example, expresses his feeling for Laura using the form considered perfect: sonnet; moreover, his love is always pure and his muse is always silent. That is how women are portrayed in most artwork: without voice and just for admiration, reflecting the social ideals of the period in which they are inserted. However, some female writers subvert such idea; this is the case, for example, of Gaspara Stampa, a poet from the italian Cinquecento. Although she follows the poetic form consecrated by Petrarch, she uses her poetry to express her feelings, becoming a female voice within an environment that offers but few opportunities for women to express themselves. This article aims to untie the figure of the woman who writes from the role model using a quote of Sibilla Aleramo, another Italian writer. Despite being separated by centuries, the prevailing vision of love and feminine in both of the authors period is that articulated by men. Then, studying what these and other women had written is of paramount importance to provide space to their (and our) voices.

Keywords: Female Literature. Gaspara Stampa. Gender role.

O amor, talvez por sua difícil compreensão, virou tema, dentre tantas outras áreas, de discussões e de obras de arte no passado e ainda hoje desperta a curiosidade da humanidade - afinal, como fala Drummond, "Que pode uma criatura senão,/ entre criaturas, amar?”’1 E é justamente com essa temática que se consagraram grandes poetas em diferentes locais e períodos; na Itália renascentista, por exemplo, é impossível não citar nomes como Dante e Petrarca, tornando-se esse último um modelo para as próximas gerações atravessando o Classicismo português com Camões e o modernismo brasileiro com Vinícius de Moraes, por exemplo - não só na temática de sua obra, mas também em sua forma.

Embora seja objeto de muita atenção e estudos, o amor também é alvo de muitas teorizações e regras, afinal, trata-se de algo subjetivo. $\mathrm{Na}$ sociedade ocidental, por exemplo, a influência do cristianismo, conforme discute Ariès 
(1987), esculpiu de maneira restrita os moldes de como o sentimento amoroso - no caso, romântico - deveria existir e ser expressado até meados do século XVIII: ele deveria ser heterossexual e puro. No Canzoniere de Petrarca, o autor retrata a considerada forma perfeita não só do poema, o soneto, mas também do sentimento, cujo objeto é Laura.

A poesia e a musa de Petrarca são sempre castas: Laura e o sentimento que desperta no autor são sublimes. "Petrarca representou suas paixões por uma mulher que está distante das coisas terrenas, mas que é motivo de um tormento quase insanável (...)" (SALES DE SOUZA, 1996, p. 2) e tal infelicidade é fundamentada na ideia de que o amor e a dama devem continuar puros, porque a mulher que não o é, seguindo os padrões da época, não pode ser digna de tamanha adoração. E, como tais regras eram ditadas pela religião, também "vale observar que, nos sonetos de Dante e Petrarca, a palavra Amor aparece com maiúscula, para representar um sentimento de amor mais voltando para a glorificação poética e para Deus, do que para a realidade concreta dos homens" (SALES DE SOUSA, 1996, p. 4). Laura, portanto, é colocada distante pelo próprio autor para que ele possa se aproximar de uma divindade superior.

É a esse papel que se restringe a presença da mulher, seja na poesia, seja no amor: ser o objeto de desejo de um homem que, para que se mantenham puros seus sentimentos e sua dama cortejada, não chega sequer a tocá-la. A fim de ilustrar quão rigoroso era essa espécie de mandamento sobre o amor, Ariès (1987, p. 157), cita um trecho extraído de um tratado sobre o casamento que se perdeu de Sêneca: "um homem sábio deve amar sua mulher com discernimento e não com paixão (...). Nada é mais imundo do que amar a sua mulher como uma amante". Nem mesmo dentro do casamento o amor deixa de ser julgado; mas, para além disso, sobre o amor de uma mulher por seu marido - já que estamos falando de casamento - não há uma linha sequer. 
Isso porque a mulher é proibida não só de ter desejos, mas de sentir: "se os maridos são convidados a amar a esposa - diligite -, estas são convidadas a ser submissas - subditae (...)" (ARIÈS, 1986, p. 158). Portanto, aquelas que não seguem esses ideais são a origem do pecado (essa ideia de perversão feminina, aliás, vem desde Eva); é dessa imagem da mulher pecaminosa de que as mulheres deveriam se afastar, segundo o modelo patriarcal e cristão da sociedade ocidental.

Entretanto, há um movimento no Cinquecento italiano em que essa falta de voz começa a ser modificada: “(...) muitas mulheres passaram a escrever e a publicar obras literárias de maneira jamais vista ou registrada até então". (SOUSA, 2011, p. 30). Nesse período o acesso à educação das famílias abastadas era o mesmo, fosse para as meninas, fosse para os meninos. Inserem-se, assim, no campo intelectual as mulheres:

(...) nas cortes italianas da Renascença era muito prestigiada a mulher que, além de apresentar beleza física, também demonstrasse publicamente conhecimento em artes como a música, a pintura, a dança e a literatura, e soubesse conversar com desenvoltura sobre outras temáticas igualmente consideradas nobres como filosofia e retórica (SOUSA, 2011, p. 28).

Consequentemente, o número de autoras também aumentou. Ainda assim, os papéis sociais seguiam rígidos para as mulheres; as cortesãs, por exemplo, desde que de classe social elevada e com conhecimentos em áreas como a literatura, tinham notoriedade nos grandes salões da Itália renascentista; mas havia ainda o estigma sobre "qualquer mulher que não vivesse sob a tutela de um homem (em razão de não ter marido, ou encontrarse separada deste), ou que tivesse relações monogâmicas, mas não conjugais". (ASOR ROSA apud SOUSA, 2011, p. 35). Dessa forma, mesmo que o cenário literário tenha sido, em partes, alterado, a sociedade ainda exigia um comportamento feminino específico. 
Sendo assim, ainda era muito arriscado para uma mulher transformar em versos sua paixão: "uma cortesã poderia fazê-lo, mas para uma mulher respeitável isso seria muito problemático"² (SMARR, 2001, p. 2). Por mais que houvesse um novo espaço para a obra feminina, ele ainda era delimitado por meio da preocupação com a reputação social. Além desse cuidado especial com o que seria escrito, havia também a dificuldade de ter uma versão própria - e masculina - de musa:

O que serviria para uma poeta como objeto admissível de devoção? Além disso, como as descrições de Laura, com seu cabelo dourado, seus olhos reluzentes e pés delicados, poderiam ser adaptados a um objeto masculino? Ou seja, como seria descrito um homem encantador? Por fim, se a castidade de Laura a torna inalcançável a Petrarca, qual é a virtude digna de elogio que pode ser atribuída a um homem que o torna igualmente inatingível?33 (SMARR, 2001, p. 2)

Fazia-se, então, necessária muita coragem para que uma mulher expusesse seus sentimentos em uma obra literária. Dentre as valentes escritoras da época - como Vitoria Collona, Veronica Franco, Tullia d'Aragona e Laura Battiferri, por exemplo - encontra-se Gaspara Stampa, de quem foram escolhidos dois poemas para discutir a presença feminina em comparação à sua imagem construída na obra de Petrarca.

Nascida em 1523, Stampa mudou-se para Veneza (um centro cultural na época) após a morte de seu pai. Lá, mesmo que sua família já não tivesse mais a condição abastada de antes, a autora pode continuar seus estudos junto de seus irmãos: "a educação dedicada aos irmãos Stampa em Veneza, a qual não era muito diferente daquela presente em outras famílias aristocráticas italianas da época, favoreceu a inserção da família na sociedade desta cidade" (SOUSA, 2011, p. 39). Colocada, portanto, nesse ambiente, Stampa pode conhecer, em 1548, o conde e mecenas Collatino di Collato, por quem se apaixonou. Embora ambos tenham tido um curto relacionamento, interrompido quando o amado foi à França em combate, a paixão ardente da autora nunca foi 
correspondida à altura. Tamanho amor e sua rejeição foram tema central de sua obra.

É impossível negar, nos escritos de Stampa, os aspectos replicados da obra de Petrarca, inclusive porque eles são colocados ali de forma explícita. Já no poema de abertura de seu livro Rime, por exemplo, a autora faz uma referência direta ao primeiro poema do Canzoniere. Percebe-se também que

\begin{abstract}
Gaspara imprime em suas composições literárias características essencialmente petrarquistas, tais como equilíbrio e harmonia na forma, predileção pelo soneto, neoplatonismo evidenciado na idealização do Amor, enfim, elementos que nos apontam para a marcante influência do bardo italiano na cultura predominante na Veneza do Cinquecento. (SOUSA, 2011, p. 53)
\end{abstract}

Entretanto, a principal diferença entre os dois poetas encontra-se que diz respeito à voz lírica e seu objeto de amor. De um lado, temos um homem, Petrarca, que expressa seu amor a uma mulher de características celestiais, Laura; do outro, temos uma mulher apaixonada, Stampa, que dá voz ao seu sentimento por um homem, Collato - e não por uma figura divina. Mais do que isso, “(...) a separação do amor entre o pecaminoso e o divino não interessa a Stampa. Pelo contrário, seu amor é terreno, onde corpo e alma são um."4 (VERNQVIST, 2013, p. 2). Lemos, por exemplo, no soneto LV:

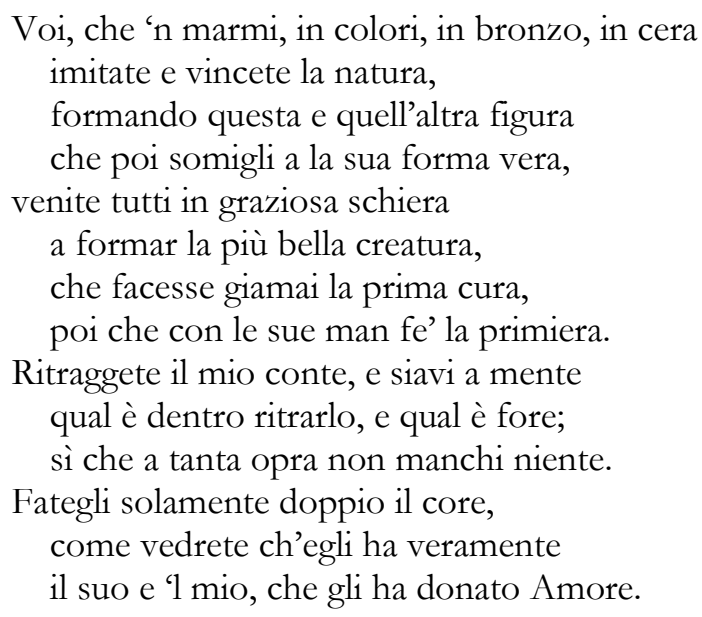

O primeiro ponto a ser observado aqui é que, embora siga a forma de Petrarca, Stampa faz de maneira sutil ${ }^{5}$ algo que o poeta não fez em sua obra: 
uma exaltação à aparência física de seu amado. Ela recorre aos artistas plásticos que trabalham em marmo, colori, bronzo e cera para recriá-lo, chamandoo, inclusive de più bella criatura. Tal ato é tido por subversivo no momento em que escreve não apenas por se tratar de uma mulher, mas também devido à cena do amor de modo geral, pois seu amor não é divino - pelo menos não só, já que envolve também o corpo, que é a parte mais humana que há. Além disso, enquanto ela pede que retratem o seu conde, não vemos nem mesmo uma menção ao sentimento dele; sua presença aqui serve unicamente como ponto de partida para a expressão do sentimento da poeta: “(...) homem transformou-se na musa calada!"” (VERNQVIST, 2013, p. 2). Os papéis, portanto, se invertem.

Ao mesmo tempo em que ousa, a autora também consegue, nos dois últimos versos, elevar o tom melancólico do poema. O seu coração já não mais lhe pertence - ele está agora mais do que nas mãos do seu amado; está junto ao seu próprio, tamanha a devoção de Stampa a Collato. E é graças ao descuidado do conde com a prenda que recebeu, que lemos no próximo soneto (LVI):

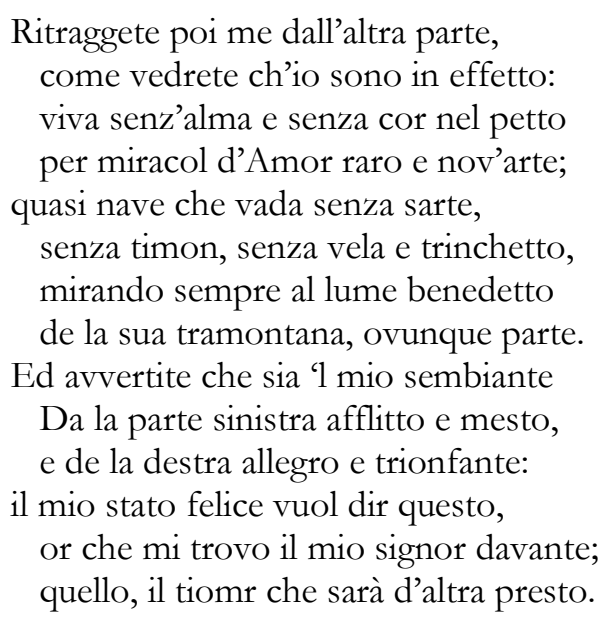

Embora não exalte seu amado, Stampa também ousa nesse poema, ao expor de forma tão crua e franca seus próprios sentimentos. Além de não ser mais dona de seu coração, o amor lhe tomou também sua alma e é sem esses 
dois elementos vitais que ela segue vivendo. E mesmo que em uma situação tão lastimável, há uma parte de seu semblante que está alegre e trionfante por ter diante de si o seu senhor. Há no último verso, porém, a maior das audácias: ao dizer que sente "il timor che sarà d'altra presto", Stampa demonstra a possibilidade de que o amado possa estar com outra mulher logo, o que indica um relacionamento fora do casamento - e eram julgadas as mulheres que participavam desses relacionamentos, mesmo que fossem monogâmicos.

A autora, porém, não se intimida e segue até o fim de sua vida escrevendo poemas que são claras declarações de amor a seu insensível amado. Diferente de Petrarca, Stampa não demonstra culpa em seus sonetos; muito pelo contrário:

\begin{abstract}
Ao culpá-lo por uma falha moral perdoável, Stampa consegue se esquivar completamente do sentimento de culpa moral ou angústia que surge na poesia de Petrarca quando ele percebe que não pode obter o que almeja, já que seu desejo é impróprio e pecaminoso. Petrarca deve combater seus próprios impulsos. Todos os sofrimentos de Stampa têm uma causa externa, não interna; seus tormentos são os de uma vítima do amor, sem peso algum na consciência ${ }^{7}$ (SMARR, 2001, p. 19).
\end{abstract}

Além de musa calada, o homem é aqui o culpado por suas ações e sentimentos. Se ela sofreu, foi por conta dele; se ela se envolveu em um relacionamento que não o matrimônio, foi por responsabilidade desse homem. A voz lírica feminina nos poemas de Stampa não só expõe seus desejos, seus temores e sentimentos, mas também se exime de qualquer pecado do qual poderia ter sido acusada.

Assim como em Petrarca, o amor de Stampa também é grafado em letras maiúsculas. Porém, enquanto nos sonetos daquele, tal recurso tem por finalidade representar o lado celestial do sentimento, nos dessa é uma forma de enfatizá-lo. Seu afeto não é uma aproximação a Deus, porque seu objeto de amor é apenas um humano - assim como ela. Stampa causa uma tensão ao usar a forma petrarquista considerada perfeita para expor um sentimento 
imperfeito. Sua escolha, porém, é muito mais verdadeira: em se tratando de assuntos terrenos, a imperfeição é um fato - da mesma forma que são os desejos, sejam eles masculinos ou femininos.

A partir dos poemas aqui selecionados, pode-se perceber também o quão inteirada das questões artísticas da época a autora estava. Ao pedir que os artistas plásticos representassem a ela e a seu amado, Stampa aprofunda ainda mais a ideia de realidade: no período da renascença, há uma vontade de representar o homem (e a mulher, claro) tal qual ele é. No soneto LV, ao falar da representação de Collato, a autora permite que pensemos sua anatomia de uma forma verossímil - e, de novo, em um amor mais carnal da autora em relação ao conde. Ao mesmo tempo, outra forma comum de representação que volta a receber prominência na sociedade da época era o nu e é justamente dele que Stampa se utiliza para retratar seus sentimentos no soneto LVI; eles estão colocados ali sem um pudor sequer, sem uma vestimenta. Se as obras plásticas representavam pessoas de maneira mais fidedigna, a poesia de Stampa também o faz, seja com o corpo, seja com as emoções.

Em um momento histórico repleto de julgamentos, a obra de Stampa não passou despercebida. Por algum tempo houve o questionamento: seria a autora uma cortesã? Foi preciso um tempo para que ela fosse lida da forma que, atualmente, parece ser a mais adequada: “(...) Gasparina se enquadra muito mais na figura de uma "vítima do amor" do que na figura de uma cortesã, dominadora das artes e armadilhas do amor" (SOUSA, 2011, p. 45). Entretanto, nos dias de hoje, ainda há certo estigma sobre a literatura feminina. Duarte, em sua seleção e tradução de poemas Três mulheres apaixonadas, faz um texto de apresentação à poesia selecionada de Stampa e diz que "quando se trata de paixão feminina, o sentimento se reveste de nuances mais delicadas, mais profundas e abrangentes" (1999, p. 7). Com essa frase, percebe-se que, mesmo séculos depois da produção literária de Stampa, o 
amor feminino segue ligado à ideia do amor mais afável. Fruto de "uma construção cultural enformada, erigida e modelada por atribuições de gênero que produzem o sexo" (AYOUCH, 2014, p. 66), ainda no século XXI, há uma tentativa de enquadrar a mulher em um modelo. E é na problemática dessa imagem socialmente construída que se coloca a necessidade de falar-se, ainda, em uma literatura feminina - e não apenas em literatura.

O cânone - machista, elitista e racista - relega ao esquecimento grandes obras que não seguem os seus padrões. Embora o interesse pela literatura feita por mulheres pareça crescer, ainda há um longo caminho até que essas autoras sejam recordadas com o respeito que lhes cabe. Stampa não é uma grande autora feminina. É uma grande autora, que cria

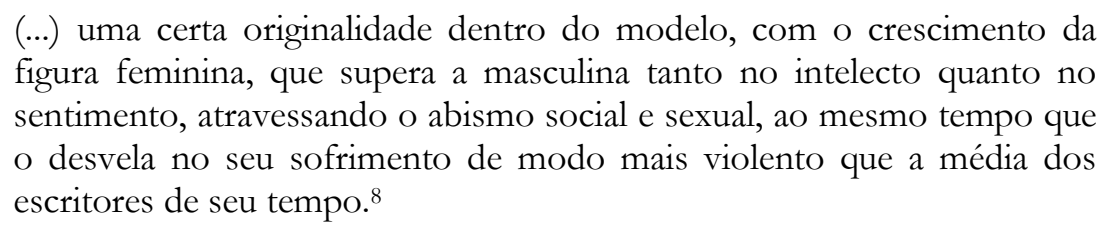

Entretanto, graças à submissão a que são colocadas as mulheres, seu nome não se coloca ao lado do de Petrarca, por exemplo. E, embora não tenha inovado na forma, ela inova de outra forma: "Stampa não é apenas uma mulher que segue um código literário criado e seguido por homens, ela escreve sua poesia com confiança, toma tom e faz ser ouvida a voz da mulher onde tradicionalmente não existe"9 (VERNQVIST, 2013, p. 2). Uma mulher que foi determinada e forte o suficiente para se expressar, ainda no Cinquecento, um momento em que se esperava a imagem beatificada. Nem todas as mulheres, entretanto, nascem santas; algumas nascem poetas e, por isso, precisam se colocar. É devido à sua insolência que as mulheres que as seguem poderão se colocar cada vez mais.

\section{Referências}


ALERAMO, Sibilla. Amo dunque sono. Milão: La Feltrinelli, 2016.

ARIÈS, Philippe. O amor no casamento. In: BÉJIN, André, orgs. Sexualidades ocidentais. São Paulo: Brasiliense, 1987. p. 153 -162,

AYOUCH, Thamy. A diferença entre os sexos na teorização psicanalítica: aporias $e$ desconstruções. Revista Braseileira de Psicanalise, Associação Brasileira de Psicanálise, 2014, 48, pp.58 - 70. ffhal01511348f

DUARTE, Sérgio. Três mulheres apaixonadas. São Paulo: Schwarcz Ltda., 1999.

SALES DE SOUSA, Francisco. A mulher na poesia de Dante, Petrarca e Boccaccio. Revista de Letras, v. 2, n. 18, 11. Jul/dez. 1996. Disponível em <http://www.periodicos.ufc.br/revletras/article/view/2069>. Acesso em: 29 ago. 2020

SMARR, Janet Levarie. Substituting for Laura: objects of desire for renaissance women poets. Comparative Literature Studies, [S.L.], v. 38, n. 1, p. 1-30, 2001. The Pennsylvania State University Press. $<$ http://dx.doi.org/10.1353/cls.2001.0008>. Disponível em: <https://www.jstor.org/stable/40247277>. Acesso em: 29 ago. 2020

SOUSA, Luciano Gomes de. Gaspara Stampa: um estudo sobre a vida e obra da poetisa renascentista italiana e a sua recep̧ão no Brasil. 2011. 154 fls. Tese (Doutorado em Letras) - Curso de Pós-Graduação em Língua, Literatura e Cultura Italianas, Universidade de São Paulo, São Paulo, 2011.

VERNQVIST, Johanna. A Female Voice in Early Modern Love Poetry - Gaspara Stampa. Trans-, [S.L.], n. 15, p. 1-8, 9 fev. 2013. OpenEdition. $<$ http://dx.doi.org/10.4 000/trans.731>. Disponível em: <https://journals.openedition.org/tr ans/731>. Acesso em: 29 ago. 2020

\footnotetext{
Notas:

${ }^{1}$ Versos do poema Amar. In: Claro Enigma. Companhia das Letras.

${ }^{2}$ Tradução própria. Original: "A courtesan might do this, but a respectable woman would find it very difficult"

3 Tradução própria. Original: "What for a female poet could serve as a permissible object of devotion? Secondly, how should the descriptions of Laura, with her curly golden hair, starry eyes, and lovely feet, be adapted for a male object? That is, how was a lovable male to be described? Thirdly, if Laura by her chastity makes herself unavailable to Petrarch, what praise worthy virtue could one attribute to a male that would make him similarly unattainable?"

${ }^{4}$ Tradução própria. Original: “(...) the division of love between sinful and heavenly is not in Stampa's interest. On the contrary, her love is earthbound where body and soul are one."
} 
${ }^{5}$ Vale ressaltar que, embora o poema selecionado recorra a sutileza ao comentar a aparência física do objeto de amor da poeta, há sonetos em que não acontece da mesma forma. No VI, por exemplo, lê-se Di pelo biodo, e di vivo colore/ Di persona alta e spazioso petto". O primeiro verso aqui colocado retoma a ideia de Petrarca, que ressalta muitas os cabelos loiros de sua musa; a seguir, entretanto, Stampa fala não só da altura de Collato, mas também da forma de seu peito.

${ }^{6}$ Tradução própria. Original: “(...) the man has become the silent muse!"

${ }^{7}$ Tradução própria. Original: "By blaming him for an excusable moral failure, Stampa can avoid completely the sense of moral guilt or anxiety that emerges in Petrarch's poetry, when he realizes that he cannot get what he wants because his desire is improper and sinful. Petrarch must combat his own impulses. Stampa's sufferings are all caused from outside, not from within; her torments are those of a victim of love, without any anguish of conscience"

8 Trecho retirado do texto "gaspara stampa (1523-54)" (2013), de Guilherme Gontijo Flores, disponível em <https://escamandro.wordpres s.com/2013/01/18/gaspara-stampa-1523-54/>. Último acesso em 29 de Agosto de 2020

9 Tradução própria. Origial: "Stampa is not only a woman following a literary code created by and for men, she writes her poetry with confidence, takes tone and makes woman's voice heard where it traditionally does not exist."

10 Sibilla Aleramo, no livro Amo, dunque sono, confessa ao seu amado "perché io son nata poeta, non santa". Dessa revelação curta, mas cheia de significado é que surgiu o título do trabalho: as poetas, ao se exporem, são colocadas no lado oposto ao das santas, porque a mulher chamada decente, segundo os padrões sociais, é a que se cala e não sente - o que é uma irrealidade e sempre será.

000/trans.731>. Disponível em: <https://journals.openedition.org/tr ans/731>. Acesso em: 29 ago. 2020 